\title{
RMetS
}

Royal Meteorological Society

\section{Examination of long-wave radiative bias in general circulation models over North Africa during May-July}

\author{
Richard P. Allan ${ }^{\mathrm{a} \star}$, Margaret J. Woodage ${ }^{\mathrm{b}}$, Sean F. Milton ${ }^{\mathrm{c}}$, \\ Malcolm E. Brooks ${ }^{\mathrm{c} \dagger}$ and James M. Haywood ${ }^{\mathrm{c}} \mathrm{d} \dagger$ \\ ${ }^{a}$ Department of Meteorology, University of Reading, UK \\ ${ }^{\mathrm{b}}$ Environmental Systems Science Centre, University of Reading, UK \\ ${ }^{\mathrm{c}}$ Met Office, Exeter, UK \\ ${ }^{\mathrm{d}}$ College of Engineering, Mathematics and Physical Sciences, University of Exeter, UK \\ ${ }^{\star}$ Correspondence to: R. P. Allan, Department of Meteorology, University of Reading, Whiteknights, Reading, RG6 6BB, UK. \\ E-mail: r.p.allan@reading.ac.uk \\ $\dagger$ The contributions of Sean Milton, Malcolm Brooks and James Haywood of Met Office, Exeter, were prepared as part of their \\ official duties as employees of the UK Government. They are published with the permission of the Controller of Her Majesty's \\ Stationary Office and the Queen's Printer for Scotland.
}

Satellite data are used to quantify and examine the bias in the outgoing long-wave (LW) radiation over North Africa during May-July simulated by a range of climate models and the Met Office global numerical weather prediction (NWP) model. Simulations from an ensemble-mean of multiple climate models overestimate outgoing clear-sky long-wave radiation (LWc) by more than $20 \mathrm{~W} \mathrm{~m}^{-2}$ relative to observations from Clouds and the Earth's Radiant Energy System (CERES) for May-July 2000 over parts of the west Sahara, and by $9 \mathrm{~W} \mathrm{~m}^{-2}$ for the North Africa region $\left(20^{\circ} \mathrm{W}-30^{\circ} \mathrm{E}, 10-40^{\circ} \mathrm{N}\right)$. Experiments with the atmosphere-only version of the High-resolution Hadley Centre Global Environment Model (HiGEM), suggest that including mineral dust radiative effects removes this bias. Furthermore, only by reducing surface temperature and emissivity by unrealistic amounts is it possible to explain the magnitude of the bias.

Comparing simulations from the Met Office NWP model with satellite observations from Geostationary Earth Radiation Budget (GERB) instruments suggests that the model overestimates the LW by $20-40 \mathrm{~W} \mathrm{~m}^{-2}$ during North African summer. The bias declines over the period 2003-2008, although this is likely to relate to improvements in the model and inhomogeneity in the satellite time series. The bias in LWc coincides with high aerosol dust loading estimated from the Ozone Monitoring Instrument (OMI), including during the GERBILS field campaign (18-28 June 2007) where model overestimates in LWc greater than $20 \mathrm{~W} \mathrm{~m}^{-2}$ and OMI-estimated aerosol optical depth (AOD) greater than 0.8 are concurrent around $20^{\circ} \mathrm{N}, 0-20^{\circ} \mathrm{W}$. A model-minus-GERB LW bias of around $30 \mathrm{~W} \mathrm{~m}^{-2}$ coincides with high AOD during the period 18-21 June 2007, although differences in cloud cover also impact the model-GERB differences. Copyright (C) Royal Meteorological Society and Crown Copyright, 2010

Key Words: mineral dust aerosol; climate models; Satellite data; radiative processes

Received 1 July 2010; Revised 13 September 2010; Accepted 29 September 2010; Published online in Wiley Online Library 7 December 2010

Citation: Allan RP, Woodage MJ, Milton SF, Brooks ME, Haywood JM. 2011. Examination of long-wave radiative bias in general circulation models over North Africa during May-July. Q. J. R. Meteorol. Soc. 137: 1179-1192. DOI:10.1002/qj.717

\section{Introduction}

The planetary energy and water cycles are fundamentally coupled (Trenberth and Stepaniak, 2004) meaning that biases in the Earth's radiative energy balance can profoundly affect the accuracy of model simulations of hydrological processes central to weather and climate prediction. While difficulties in the representation of cloud processe lead to 
substantial uncertainty in numerical weather and climate prediction (e.g. Bony et al., 2006; Allan et al., 2007), the presence of aerosol confounds atmospheric modelling by impacting the radiative balance with additional influences on radiative feedbacks and microphysical processes (Forster et al., 2007). While the influence of aerosol on shortwave radiative fluxes is of great importance to climate via their direct and indirect radiative impact (Forster et al., 2007), their influence on the Earth's greenhouse effect has received less attention, in part due to the small long-wave (LW) radiative effect of fine-mode anthropogenic aerosol particles.

Recent work has suggested a substantial radiative impact of larger aerosol particles such as desert dust on the LW radiative balance at the top of the atmosphere (Zhang and Christopher, 2003; Haywood et al., 2005; Christopher et al., 2008) and at the surface (Slingo et al., 2006) over North Africa; this led to a more detailed investigation, both in situ and remotely sensed, as part of the Geostationary Earth Radiation Budget (GERB) Intercomparison of Longwave and Short-wave fluxes (GERBILS) field campaign (Haywood et al., 2011) during June 2007. In considering the processes operating at relatively small time and space-scales, it is informative to examine the nature of model radiative bias over the entire North Africa region across many years, thereby placing detailed measurements in the context of the long-term climatology. Based upon previous analysis of model and satellite data (Haywood et al., 2005; Allan et al., 2007), the radiative bias was found to be maximum during the May-July period; by August, the increased occurrence of cloud as part of West African monsoon systems obscures the evaluation of dust radiative effect. Here we provide a broad context by evaluating a range of global atmosphere-only general circulation models over North Africa during May-July, centred upon the month of the GERBILS campaign, covering the period 1985-2009.

\section{Models and satellite datasets}

\subsection{Climate models}

In section 3 we examine output from eight atmosphereonly climate models, forced with the observed sea surface temperature (SST) record over the period 1979-2000. The models, listed in Table I, are described in detail by Randall et al. (2007) and at http://www-pcmdi.llnl.gov. Four of the models include parametrizations for the radiative impact of mineral dust (Table I), prescribing climatological concentrations, although the LW radiative effects of dust aerosol were neglected in the CCSM3 model.

\subsection{HiGEM model}

In section 4 we explore in more detail the impact of mineral dust simulations within a high-resolution $\left(1.25^{\circ}\right.$ longitude $\times 0.83^{\circ}$ latitude, 38 vertical levels) version of the Hadley Centre HadGEM1 climate model, HiGEM (Shaffrey et al., 2009). We employed the atmosphere component of this model (HiGAM) which was supplied with SST boundary conditions generated from observations. Simulations were conducted over the period 1983-2000. Over the Sahara, surface albedo over bare soil was prescribed, based upon data from the Moderate-Resolution Imaging Spectroradiometer (MODIS) satellite instrument (Houldcroft et al., 2009). A prognostic dust scheme, based on that developed by
Woodward (2001), was employed, using six particle-size bins, a dust source ancillary file and a friction velocity threshold mobilisation scheme which depends upon particle diameter and soil moisture content in the top $10 \mathrm{~cm}$ soil layer. A full description is included in Woodage et al. (2010); some tuning of the dust emission parameters was required to produce realistic dust loadings in HiGAM. Note that the scheme is not the same as the HadGEM2 scheme described in Johnson et al. (2011), although they are both stages along the development path from the original Woodward (2001) formulation. Dust is fully interactive with representation of direct dust radiative effects and feedbacks. Indirect feedbacks involving cloud microphysics were not considered.

\subsection{Earth radiation budget satellite data}

Climate model simulations of the top-of-atmosphere radiation budget are compared with global monthly mean satellite data from the Earth Radiation Budget Satellite (ERBS) and the Clouds and the Earth's Radiant Energy System (CERES) instruments (details in Wielicki et al., 2002, and references therein). The satellite datasets convert measured radiance to radiative fluxes using angular dependence models and scene type information. The PFM CERES instrument on board the Tropical Rainfall Measurement Mission (TRMM) satellite was used to provide data for 1998. We considered version ES4_TRMM-PFM_EDITION2_015013 which used a similar processing system to the ERBS data. We also considered the FM1 CERES instrument on board the Terra satellite for the period 2000-2005, employing an updated processing system including improved angular dependence models (version CER_SRBAVG1_Terra-FM1MODIS_Edition2D_015026 with user-applied Revision 1 to account for spectral darkening of the short-wave channels). The main source of uncertainty in the CERES and ERBS radiative fluxes is absolute calibration which is quoted as being $2 \%$ in the short-wave (SW) channel and $1 \%$ in the total channel (Loeb et al., 2009); the LW error is estimated by Loeb et al. (2009) to be $1.5 \%$ of the mean flux, or around $4.5 \mathrm{~W} \mathrm{~m}^{-2}$ for a LW flux of $300 \mathrm{~W} \mathrm{~m}^{-2}$, typical of desert conditions. (Matthews, 2009) argues, based upon consideration of ground calibration techniques and vicarious calibration using deep convective cloud tops, that current CERES products underestimate daytime LW by around $0.75 \%$ and SW albedo by $1-3.5 \%$. We assume a monthlymean LW uncertainty of around $5 \mathrm{~W} \mathrm{~m}^{-2}$ for ERBS and CERES datasets.

\subsection{Met Office global NWP model}

Output from the global version of the Met Office numerical weather prediction (NWP) model is examined in sections 5-6; details of the model are described by Milton et al. (2008). The model parametrizations are similar to the atmospheric climate model component of HadGEM1 and it uses a simple background aerosol climatology, although not including mineral dust. The model has been continually updated over the period of study. The main changes are: the introduction of $4 \mathrm{D}$ Var data assimilation on 5 October 2004; implementation of HadGEM1 physics on 18 January 2005; resolution enhancement from $0.833^{\circ}$ longitude $\times 0.556^{\circ}$ latitude with 38 levels in the vertical to $0.5625^{\circ}$ longitude $\times 0.375^{\circ}$ latitude with 50 levels in the vertical on 13 December 2005; updates to 
Table I. Observed outgoing long-wave (LW) and clear-sky long-wave (LWc) radiation and mean model biases ( $\triangle$ LW and $\triangle$ LWc) relative to CERES/Terra climatology (2000-2005), ERBS (1985-1989), CERES/TRMM (1998) and CERES/Terra (2000) for May-July over the region shown in Figure 2.

\begin{tabular}{|c|c|c|c|c|c|c|c|c|c|}
\hline \multicolumn{2}{|l|}{ Dataset } & \multicolumn{2}{|c|}{ CERES Clim } & \multicolumn{2}{|c|}{ ERBS } & \multicolumn{2}{|c|}{ CERES/TRMM } & \multicolumn{2}{|c|}{ CERES/Terra } \\
\hline & & LW & LWc & LW & LWc & LW & LWc & LW & LWc \\
\hline Observations & & 277.5 & 293.9 & 274.3 & 292.9 & 277.3 & 296.0 & 278.4 & 294.7 \\
\hline & Dust aerosol? & $\Delta \mathrm{LW}$ & $\Delta \mathrm{LWc}$ & $\Delta \mathrm{LW}$ & $\Delta \mathrm{LWc}$ & $\Delta \mathrm{LW}$ & $\Delta \mathrm{LWc}$ & $\Delta \mathrm{LW}$ & $\Delta \mathrm{LWc}$ \\
\hline CNRM-CM3 & Yes & 8.0 & 11.4 & 8.5 & 12.7 & 13.6 & 13.7 & 6.5 & 9.1 \\
\hline INM-CM3.0 & & 7.4 & 4.8 & 10.8 & 6.7 & 8.1 & 3.8 & 8.9 & 5.7 \\
\hline IPSL-CM4 & & 11.0 & 13.9 & 11.5 & 15.3 & 14.5 & 13.4 & 11.6 & 13.8 \\
\hline MIROC3.2hires & Yes & 7.8 & 9.0 & 11.2 & 11.9 & 8.8 & 7.7 & 7.8 & 8.5 \\
\hline MIROC3.2medres & Yes & 3.4 & 5.6 & 7.3 & 8.6 & 5.4 & 4.6 & 6.1 & 5.9 \\
\hline MRI-CGCM2.3.2a & & 6.9 & 2.8 & 9.7 & 5.0 & 8.0 & 2.7 & 9.3 & 3.4 \\
\hline NCAR-CCSM3.0 & Yes (SW only) & 10.7 & 10.6 & 14.7 & 14.2 & 14.5 & 11.3 & 13.7 & 11.9 \\
\hline UKMO-HADGEM1 & & 16.4 & 13.3 & 19.5 & 15.3 & 20.0 & 14.2 & 18.8 & 14.0 \\
\hline Ensemble mean & & 9.0 & 8.9 & 11.7 & 11.2 & 11.6 & 8.9 & 10.3 & 9.0 \\
\hline
\end{tabular}

the convection and boundary-layer parametrizations during 2006; improved surface albedo and introduction of biogenic aerosol climatology on 15 May 2007; multiple updates to model physics and data assimilation on 25 November 2008 (further details in Allan et al., 2007). We utilize simulations of radiative fluxes based upon 1200 UTC analyses and $3 \mathrm{~h}$ forecasts, valid at 0900 and 1500 UTC, over the period 2003-2008. Allan et al. (2005) provide further details of the methodology.

\subsection{Geostationary Earth Radiation Budget (GERB) data}

The NWP model simulations are compared with measurements from the GERB instruments on board the Meteosat- 8 and Meteosat- 9 satellites. We use averaged, rectified, geolocated (ARG) level-2 broadband flux products, provided at a frequency of approximately $17 \mathrm{~min}$. We use the closest time to the NWP model time step (for 1200 UTC comparisons this is $1200-1220$ UTC prior to 13 December 2005 and 1200-1215 UTC thereafter), interpolating the GERB data from its approximately $50 \mathrm{~km}$ grid to the NWP model resolution prior to 13 December 2005. The period March 2004 to May 2007 contains the validated Edition 1 GERB dataset which converted measured radiance to radiative flux using angular dependence models using a fixed processing system (Clerbaux et al., 2008a,b). Prior to this period, the GERB data operated under a preliminary processing standard. From May 11 2007, a new GERB instrument using the second Spinning Enhanced Visible and Infra-Red Imager (SEVIRI) instrument for processing became operational. The GERBILS campaign is within this final period. Initial comparisons find that the new GERB instrument produces higher LW than the original GERB instrument of up to $1.5 \%$, the difference being largest at midday (Bantges et al., 2010). For $\mathrm{LW}=300 \mathrm{~W} \mathrm{~m}^{-2}$, typical of clear-sky desert conditions for June, this corresponds to a difference of $4.5 \mathrm{~W} \mathrm{~m}^{-2}$, which would tend to reduce positive model minus GERB LW bias for the latter period. The discrepancy between the GERB instruments relates to the quartz filter transmission which will be improved in the final release version of the GERB data from 2007 onwards (Bantges et al., 2010). The estimated GERB uncertainty is $1 \%$ for LW and $2 \%$ for the SW channel, determined primarily by the spectral response characterization (Clerbaux et al., 2009). Applying these estimated uncertainties to Eq. A2 of Loeb et al. (2009) with 1200 UTC GERB LW and SW averages for the region $10^{\circ} \mathrm{W}-30^{\circ} \mathrm{E}, 10-30^{\circ} \mathrm{N}\left(\mathrm{SW}=363 \mathrm{~W} \mathrm{~m}^{-2}\right.$, $\mathrm{LW}=313 \mathrm{~W} \mathrm{~m}^{-2}$ ), and assuming a correlation between SW and total channel uncertainty of 0.9 based upon CERES measurements, the error in LW at 1200 UTC is estimated to be $4.6 \mathrm{~W} \mathrm{~m}^{-2}$. GERB SW was found to be substantially larger than CERES, by 7.5\% (Clerbaux et al., 2009); this discrepancy may be partially explained by CERES ground calibration issues (Matthews, 2009). Clerbaux et al. (2009) also found LWc to be around $2 \%$ or $5 \mathrm{~W} \mathrm{~m}^{-2}$ lower than CERES. An additional uncertainty in the ERBS, CERES and GERB radiative fluxes arises because an angular dependence model for mineral dust aerosol is not available for converting radiances to fluxes. Given the additional uncertainty relating to radiance to flux conversion and issues with filter transmission mentioned above, we estimate a LW uncertainty of $10 \mathrm{~W} \mathrm{~m}^{-2}$ for instantaneous daytime GERB data.

\subsection{Additional datasets}

\subsubsection{CRUTEM3 near-surface temperature}

We also consider near-surface temperature measurements from the Climatic Research Unit surface air temperature observations (CRUTEM3; Jones et al., 1999; Brohan et al., 2006). These are derived from homogenized, qualitycontrolled, monthly averaged temperature measurements, with additional removal of duplicate records and bad values based upon comparison with reanalysis data, augmented by visual inspection. Data are provided on a $5 \times 5$ degree grid, compiled from all-station anomalies within the domain but excluding station outliers in excess of five standard deviations. For comparisons with model values, the CRUTEM3 May-July mean temperature anomalies are added to the 1961-1990 climatological values at each $5 \times 5$ degree grid box.

\subsubsection{SEVIRI imager data}

The $10.8 \mu \mathrm{m}$ and $12 \mu \mathrm{m}$ channel brightness temperature from the SEVIRI imager are considered for June 2007. 
(a) LW Difference $\left(\mathrm{Wm}^{-2}\right)$

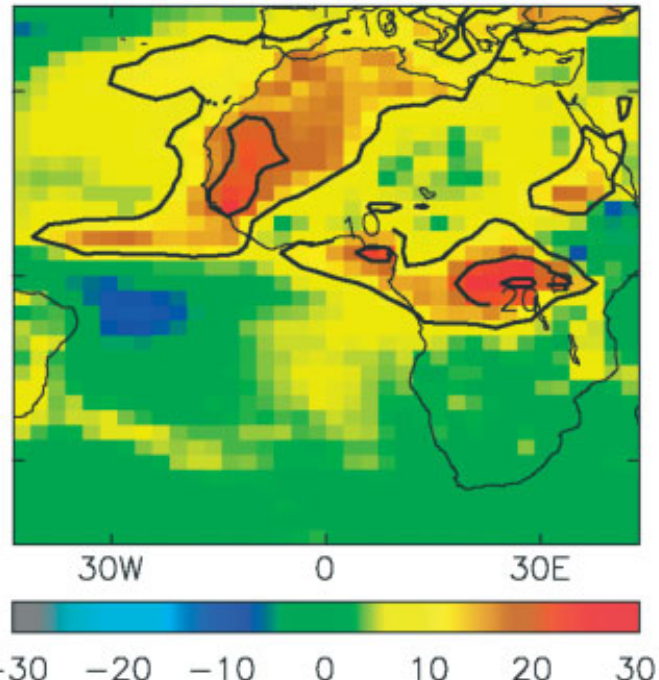

(c) LW+SW Difference $\left(W^{-2}\right)$

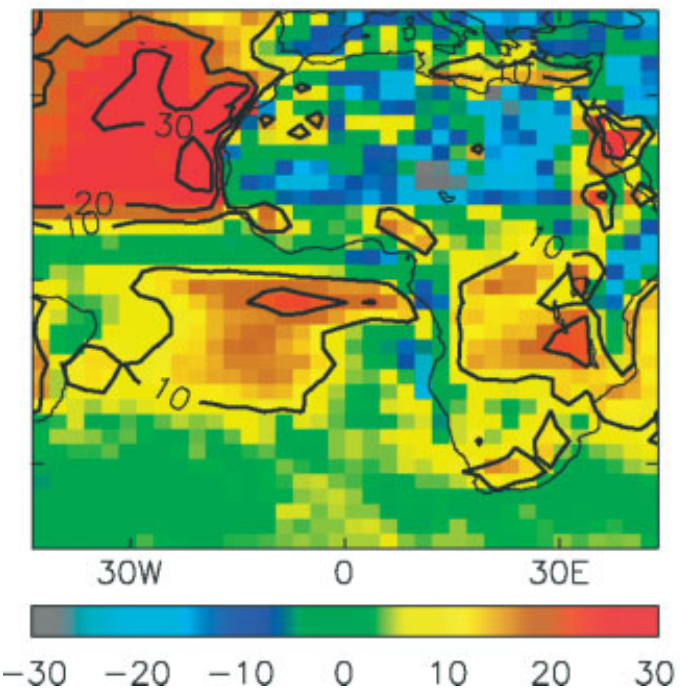

(b) SW Difference $\left(\mathrm{Wm}^{-2}\right)$

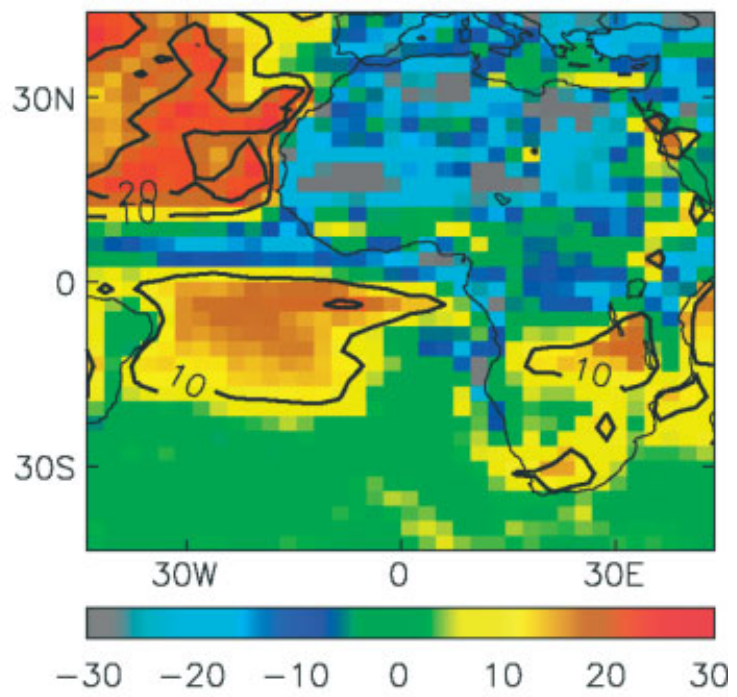

(d) Tair Difference (K)

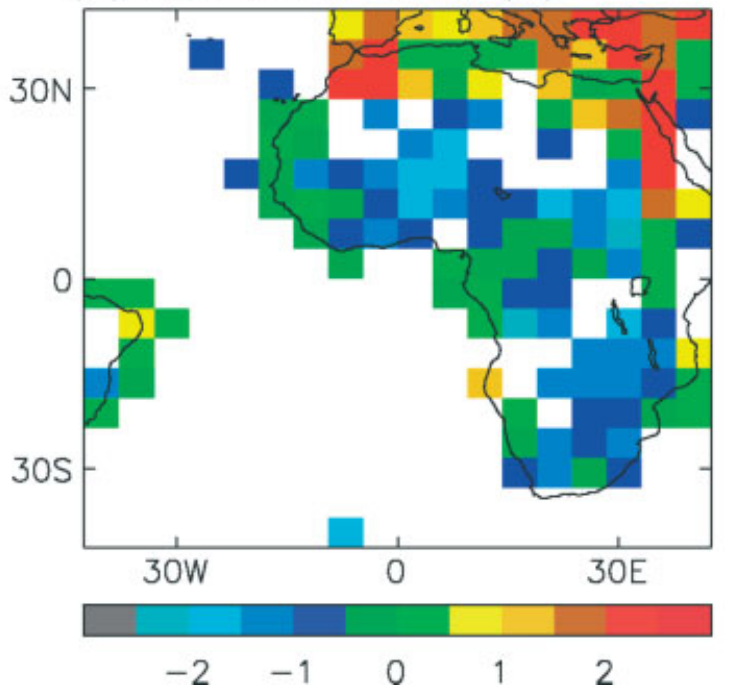

Figure 1. Model ensemble mean minus Earth Radiation Budget Satellite observed diurnally averaged top-of-atmosphere outgoing (a) long-wave (LW), (b) short-wave (SW) and (c) LW plus SW radiation and (d) model minus CRUTEM3 observed surface air temperature for May-July $1985-1989$.

Additionally, for clear-sky comparisons between the NWP model and satellite data, we combine SEVIRI visible channel estimates of cloud cover (Ipe et al., 2004) with model cloud fraction diagnostics. These are combined to construct clear-sky estimates that are consistent in space and time, thereby avoiding inconsistent sampling present for the comparisons between the monthly mean ERBS and CERES data and climate model diagnostics. All SEVIRI-based data are considered here at the horizontal resolution of the NWP model.

\subsubsection{Aerosol satellite data}

We use monthly mean AOD estimates at $0.55 \mu \mathrm{m}$ from version AM1_CGAS__F15_0031 of the Multi-Angle Imaging Spectroradiometer (MISR; Diner et al., 2001). Additionally we use daily $1^{\circ}$ resolution level 3 Aerosol Index (AI) data based upon $0.36 \mu \mathrm{m}$ radiance measurements from the Total Ozone Mapping Spectrometer (TOMS) Ozone Monitoring Instrument (OMI) (Torres et al., 2002).

\section{Climatological radiative bias}

We first consider the difference in radiative fluxes between eight climate models, listed in Table I, and satellite data over the Africa-Atlantic region. In particular, first we assess whether LW radiative flux bias over the North Africa region is significant with respect to the larger region and relative to biases in SW radiative fluxes. Figure 1 shows the diurnally averaged radiative flux difference between the model ensemble mean and ERBS data over the period 1985-1989, for May-July monthly averages. The models overestimate outgoing LW radiation over central and western Africa (Figure 1(a)). The LW discrepancy reaches up to $30 \mathrm{~W} \mathrm{~m}^{-2}$ over the Congo $\left(30^{\circ} \mathrm{E}, 0^{\circ} \mathrm{S}\right)$ and is most likely to relate to model underestimation of cirrus outflow from convection since the LW bias is of opposite sign but of larger magnitude than the SW bias and is substantially smaller $\left(<10 \mathrm{~W} \mathrm{~m}^{-2}\right)$ for clear-sky LW comparisons. There is an overestimate in the reflected SW radiation over the subtropical Atlantic (Figure 1(b)) by more than $20 \mathrm{~W} \mathrm{~m}^{-2}$ where regions of low-altitude stratiform and 

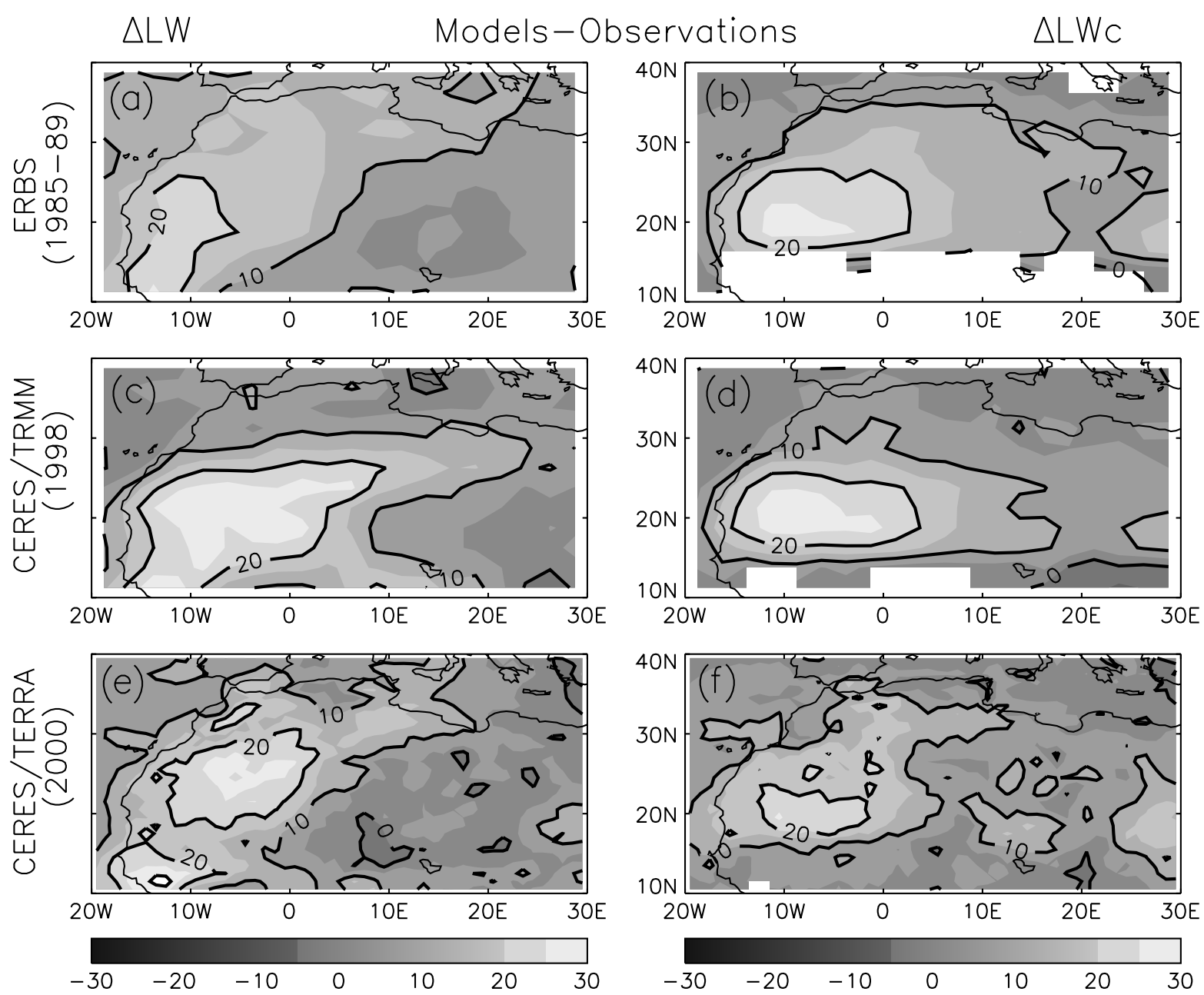

Figure 2. Model ensemble mean bias in May-July diurnally averaged ( $a, c, e)$ all-sky and (b, d, f) clear-sky outgoing long-wave radiation relative to (a, b) ERBS, (c, d) CERES/TRMM and (e, f) CERES/Terra SRBAVG GEO.

trade cumulus cloud are prevalent. Similar differences were also documented by Allan et al. (2007) in comparisons between the Met Office global forecast model and GERB satellite data, and are thought to relate to convective parametrization and to an overestimate in stratocumulus cloud liquid water and reflectivity. Also evident is a model tendency to underestimate the reflected SW over land, in particular for the Sahara region, where surface albedo may be inaccurate. Similar results are obtained by comparing the model climatology (1979-2000) with the CERES/Terra data for 2000-2005, although differences over the stratocumulus regions are around $10 \mathrm{~W} \mathrm{~m}^{-2}$ larger in magnitude (not shown), likely to relate to calibration uncertainty (Matthews, 2009).

Also evident in Figure 1(a) are LW differences greater than $20 \mathrm{~W} \mathrm{~m}^{-2}$ over the western Sahara region. Haywood et al. (2005) argued that a similar bias between the Met Office NWP model and geostationary satellite data related to mineral dust aerosol. While positive model LW bias over the subtropical Atlantic adds to the substantial positive SW bias, over the west Sahara the SW and LW biases are of opposite sign, resulting in a small net LW plus SW radiative bias (Figure 1(c)). Over southern Africa, an overestimate in reflected SW radiation is consistent with a model cold bias relative to surface observations from CRUTEM3. On inspecting the clear-sky SW difference between models and satellite data (not shown), it was found that up to $\sim 10 \mathrm{~W} \mathrm{~m}^{-2}$ of this bias can be explained by the cloud-free comparisons. A model warm bias over southern Europe is also consistent with underestimations in reflected SW radiation by the models (Figure 1(d)); on inspecting clearsky SW fluxes, it was found that this bias is most likely to be related to model errors in cloud cover. This is not the case for the majority of North Africa where the models are too cold by up to $2 \mathrm{~K}$ yet reflect too little SW radiation back to space due to an underestimation in surface albedo. Unrealistic sensible and latent heat fluxes may be of importance (e.g. Milton et al., 2008), but this analysis is beyond the scope of the present study.

A model warm bias over the Black Sea region and the Atlas mountains is qualitatively consistent with too much LW emission to space over these regions. However, the model cold bias over North Africa (Figure 1(d)) cannot explain the overestimation in model outgoing LW radiation here (figure 1(c)). To investigate further the causes of the LW discrepancy, we now consider the North Africa region in more detail. Figure 2 displays model minus observed differences in outgoing LW radiation for three periods and for all-sky LW and clear-sky LW (LWc) radiative fluxes. Clear-sky fluxes are computed in the models by ignoring the radiative effects of clouds in separate diagnostic calculations. This is not possible for the satellite data: here clear-sky radiative fluxes are estimated only for pixels determined to be cloud-free by imaging data. Allan and Ringer (2003) 
(a) Model(nodust)-CERES

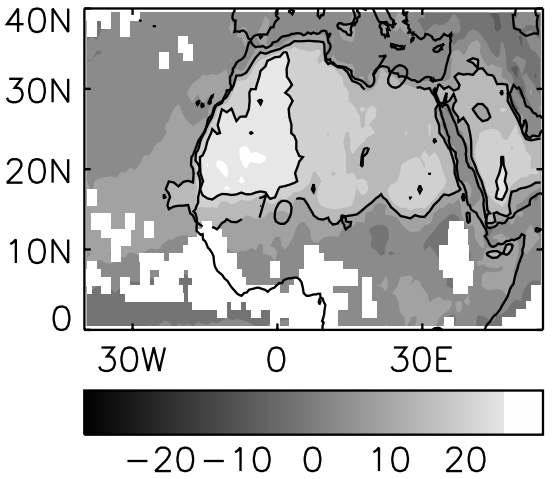

(b) Model(dust)-CERES

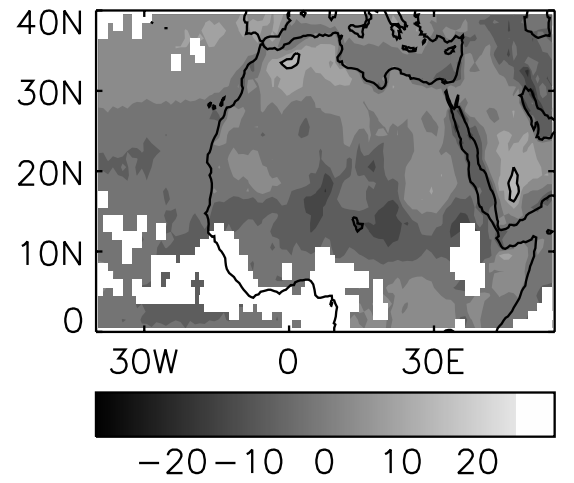

(c) Model(no dust-dust)

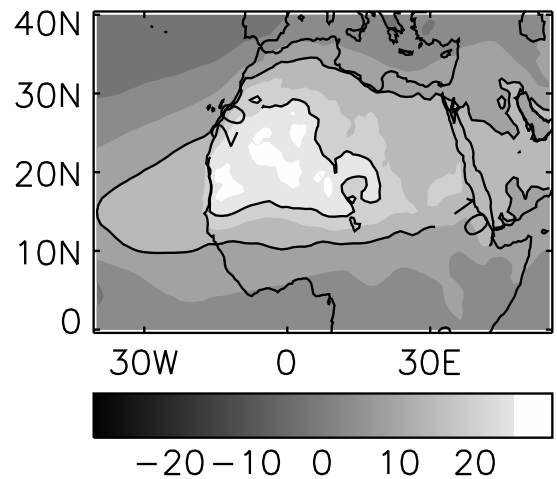

Figure 3. Clear-sky outgoing long-wave radiation differences $\left(\mathrm{W} \mathrm{m}^{-2}\right.$ ) between HiGAM climate model (1983-2000) and CERES SRBAVG GEO observations (2000-2005) for May-July climatology where (a) dust is not included in HiGAM, (b) a dust scheme is incorporated within the model. (c) shows the no-dust minus dust model differences.

found this sampling discrepancy is considerable for cloudy regions of the Tropics, producing a negative model bias in LWc of up to around $15 \mathrm{~W} \mathrm{~m}^{-2}$. This bias is smaller for less cloudy regions, such as North Africa, and is the opposite sign of the model LWc bias shown in Figure 2.

The LW discrepancy identified for 1985-1989 (Figure 2(a)) is more extensive in 1998 in comparison with CERES/TRMM (Figure 2(c)) and is also present in 2000 in comparisons with CERES/Terra data (Figure 2(e)). This discrepancy could be explained by an underestimate in model cloud cover. However, when comparing LWc, to remove the effect of cloud (Figure 2(b,d,f)), although the spatial structure of the model-observation differences is altered, the model overestimate remains. This is most pronounced for the region centred around $10^{\circ} \mathrm{W}, 20^{\circ} \mathrm{N}$.

For the region shown in Figure 2, the model ensemble mean LW bias ranges from 9 to $12 \mathrm{~W} \mathrm{~m}^{-2}$ depending upon the observations used (Table I). The LWc bias is of similar magnitude but smaller by up to $25 \%$, depending upon which climate model is considered. The IPSL and HadGEM1 models exhibit the largest bias, greater than $10 \mathrm{~W} \mathrm{~m}^{-2}$; both models did not include mineral dust aerosol. The INMCM, MIROC medium resolution and MRI CGCM2 models produce the smallest differences, closer to $5 \mathrm{~W} \mathrm{~m}^{-2}$, although of these models only MIROC includes mineral dust aerosol. Considering the smaller region $15^{\circ} \mathrm{W}-15^{\circ} \mathrm{E}$, $15-30^{\circ} \mathrm{N}$ increases the differences; LWc differences increase by about $5-10 \mathrm{~W} \mathrm{~m}^{-2}$ for the ensemble mean and are around $20 \mathrm{~W} \mathrm{~m}^{-2}$ for HadGEM1 and IPSL.

In summary, comparisons between a range of atmosphere-only climate models and a variety of satellite measurements demonstrate a discrepancy in outgoing LW radiation of order $10-20 \mathrm{~W} \mathrm{~m}^{-2}$ over the west Sahara region. This bias remains when removing cloud radiative effects from the analysis and is significant compared to known model biases in the LW and SW radiative fluxes relating to cloud processes and surface properties. We now examine the causes of the LWc bias in more detail.

\section{Examination of the LW radiative bias using a high- resolution climate model}

We now analyse in more detail the LW radiative bias using the HiGAM climate model, described in section 2. Simulations with and without the radiative effects of mineral dust aerosol are considered.

Copyright (C) Royal Meteorological Society and Crown Copyright, 2010

\subsection{Climatological radiative effect of dust aerosol}

Figure 3 shows May-July climatological differences in LWc for the North Africa region between HiGAM and CERES satellite data. When dust effects are not represented, the model overestimates monthly mean LWc by more than $20 \mathrm{~W} \mathrm{~m}^{-2}$ over the western Sahara (Figure 3(a)). When interactive dust is included in the model, this discrepancy is removed (Figure 3(b)). The model without dust minus the model with dust displays differences in LWc of around $20 \mathrm{~W} \mathrm{~m}^{-2}$ over the western Sahara, consistent with analysis by Woodage et al. (2010).

Model minus CERES climatological differences over the region considered in Table I are comparable with the lowerresolution HadGEM1 model when dust is not included (HiGAM minus CERES differences are $14.3 \mathrm{~W} \mathrm{~m}^{-2}$ for LW and $12.1 \mathrm{~W} \mathrm{~m}^{-2}$ for LWc). Mean differences over this region are smaller in magnitude than $2 \mathrm{~W} \mathrm{~m}^{-2}$ when dust is included.

\subsection{Sensitivity of $L W$ radiative bias to surface temperature and emissivity}

Inclusion of the interactive dust scheme in the HiGAM model removes much of the LW radiative bias with respect to CERES measurements. However, model bias in surface temperature and emissivity also potentially influence the simulations of LW radiative fluxes over the North Africa region. To examine this, experiments were performed with HiGAM in which surface temperature and emissivity were perturbed separately, diagnostically calculating the effect on the top-of-atmosphere outgoing LW radiation over 1-10 July 2000. Although realistic SSTs are prescribed in these simulations, these dates are chosen to represent the seasonal conditions pertinent to the $\mathrm{LW}$ radiative bias rather than accurately capture the precise meteorology during this period.

We considered an increase in surface temperature of $1 \mathrm{~K}$ and a reduction in broadband surface emissivity from its prescribed value of 1.0 to 0.9 . The dust radiative effects were turned off in these calculations. Using the resulting sensitivity of LWc to these perturbations, the estimated change in surface temperature or surface emissivity required to explain the model minus CERES LWc difference in Figure 3(a) was computed (Figure 4). These calculations are simplistic since they do not account for feedbacks in response 
(a) Surface Emissivity Change

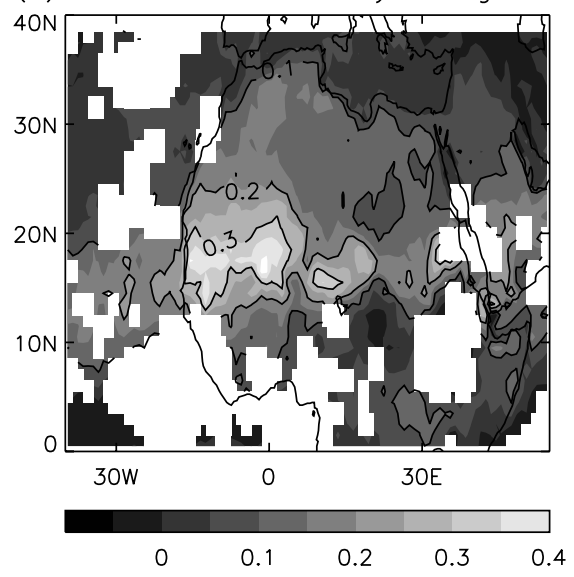

(b) Temperature Change ( $K$ )

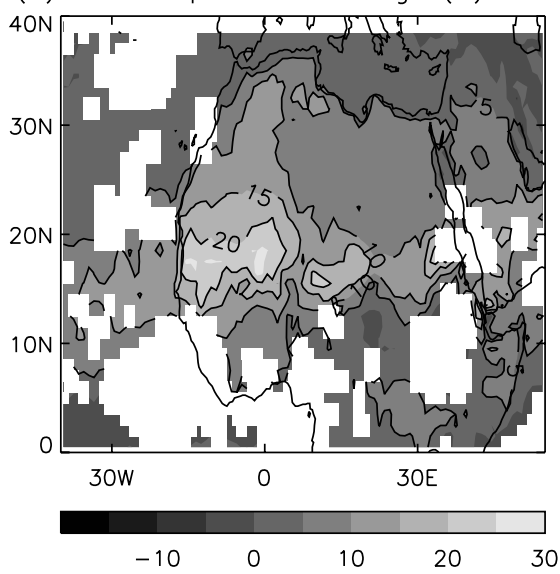

(c) HiGAM-CRU $1.5 \mathrm{~m}$ Temperature (K)

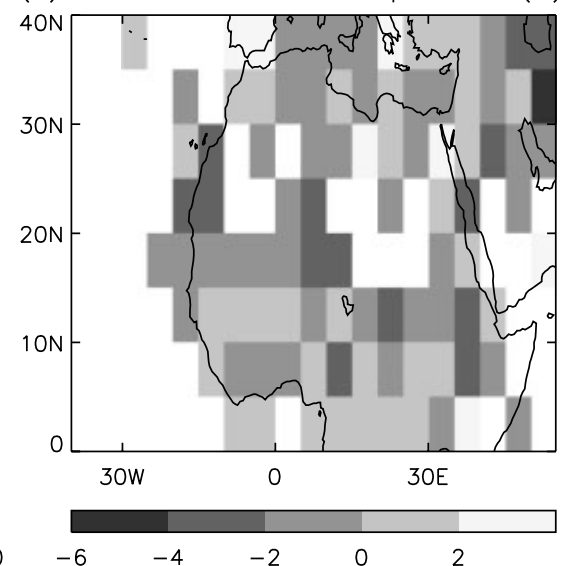

Figure 4. Positive bias in (a) surface long-wave emissivity and (b) surface temperature (K) required to explain clear-sky long-wave discrepancy in Figure 3(a) based upon perturbation experiments for $3 \mathrm{~h}$ frequency simulations of HiGAM for 1-10 July 2000. (c) shows HiGAM minus Climatic Research Unit (CRU) $1.5 \mathrm{~m}$ temperatures (CRUTEM3) for May-July 1983-2000.

to the perturbations and may be unphysical. Nevertheless they serve as a useful guide to the magnitude of model errors required to explain the LWc discrepancy.

Figure 4(a) shows that an overestimate in surface emissivity greater than 0.15 (an absolute broadband surface emissivity of 0.85 ) would be required to explain the model LWc bias over the west Sahara region. Osborne et al. (2011) measured spectral surface emissivity as low as 0.7 in the window region of the LW spectrum $\left(1070-1220 \mathrm{~cm}^{-1}\right)$ although this rises to above 0.9 at $1300 \mathrm{~cm}^{-1}$ and below $1000 \mathrm{~cm}^{-1}$. Haywood et al. (2005) argued that broadband surface emissivity less than 0.90 is uncommon and so therefore the emissivity error is unlikely to fully explain the LWc bias over the west Sahara region.

We also ask whether the model temperature bias can explain the LWc discrepancy. Based upon the sensitivity test in Figure 4(b), overestimates in model surface temperature greater than $10 \mathrm{~K}$ are required to explain the model bias in LWc. Comparisons between $1.5 \mathrm{~m}$ temperature simulated by HiGAM and CRUTEM3 observations show that this is not the case (Figure 4(c)). The model displays a cold bias over the Sahara rather than a warm bias, consistent with results from the fully coupled atmosphere-ocean version of HiGEM (Shaffrey et al., 2009) and also with the climate models considered in section 3 (Figure 1(d)). Comparisons of HiGAM simulations for May to July 1983-2000 with data from Niamey in 2006 (Slingo et al., 2008) also suggest a cold bias: the model underestimates surface skin temperature by around $2 \mathrm{~K}$ and $1.5 \mathrm{~m}$ temperature by less than $1 \mathrm{~K}$, although these are subject to substantial spatial sampling differences.

In summary, the models considered generally exhibit a cold bias over northern Africa rather than a substantial warm bias of more than $10 \mathrm{~K}$ required to explain excessive clear-sky LW emission to space. Unrealistic reductions in emissivity are necessary to explain the LWc bias over the west Sahara, although they may be important elsewhere. These findings are consistent with the analysis of Haywood et al. (2005), who also estimated the impact of SW radiative flux errors upon surface temperatures and hence on the outgoing LWc.

\subsection{Diurnal radiative effect of dust aerosol at the surface and} top of atmosphere

The radiative impact of mineral dust aerosol was detected both at the top of the atmosphere and at the surface during a major dust storm in March 2006 by Slingo et al. (2006). Using the HiGAM simulations, it is possible to estimate and assess the surface radiative impact of increasing dust aerosol concentration. A further experiment was performed, this time using the simulations containing fully interactive mineral dust arosol. In these experiments, in addition to standard radiative computations every $3 \mathrm{~h}$, an additional $3 \mathrm{~h}$ diagnostic calculation was performed where dust concentration was increased by $10 \%$. For the region considered in Figure 4, the surface and top-of-atmosphere change in LW was calculated.

Figure 5(a) shows the change in surface downward and top-of-atmosphere upward LW radiation for grid points containing less than $5 \%$ cloud cover over the region $15-30^{\circ} \mathrm{N}, 15^{\circ} \mathrm{W}-5^{\circ} \mathrm{E}$. The relationship between surface and top-of-atmosphere LWc response to a $10 \%$ increases in aerosol concentration is displayed for 0000 and 1200 UTC. Reductions in outgoing LW radiation and increases in downward LW radiative flux of up to around $5 \mathrm{~W} \mathrm{~m}^{-2}$ are evident at 1200 UTC, the response at the surface and top of atmosphere being comparable. Applying a linear leastsquares fit to the data points indicates that a reduction in top-of-atmosphere LWc of $0.83 \mathrm{~W} \mathrm{~m}^{-2}$ is associated with a $1 \mathrm{~W} \mathrm{~m}^{-2}$ increase in surface downward LWc. At 0000 UTC, the sensitivity is smaller, approximately half the surface response.

The diurnal cycle of dust radiative effect is explained both by changes in temperature lapse rate and the evolution of the planetary boundary layer. Haywood et al. (2005) point out that the direct top-of-atmosphere LWc effect depends on the difference between the emitting temperature of the aerosol and that of the surface, becoming zero when the emitting temperatures are equal. For HiGAM, surface minus atmospheric emitting temperature is a maximum at 1200 UTC, with a substantial difference in temperature lapse rate in the lowest $500 \mathrm{~m}$ (Figure 5(b)), so we would expect maximum impact on LWc at that time. In addition, the diurnal evolution of the boundary layer over the Sahara influences the magnitude of the dust loadings and its vertical 

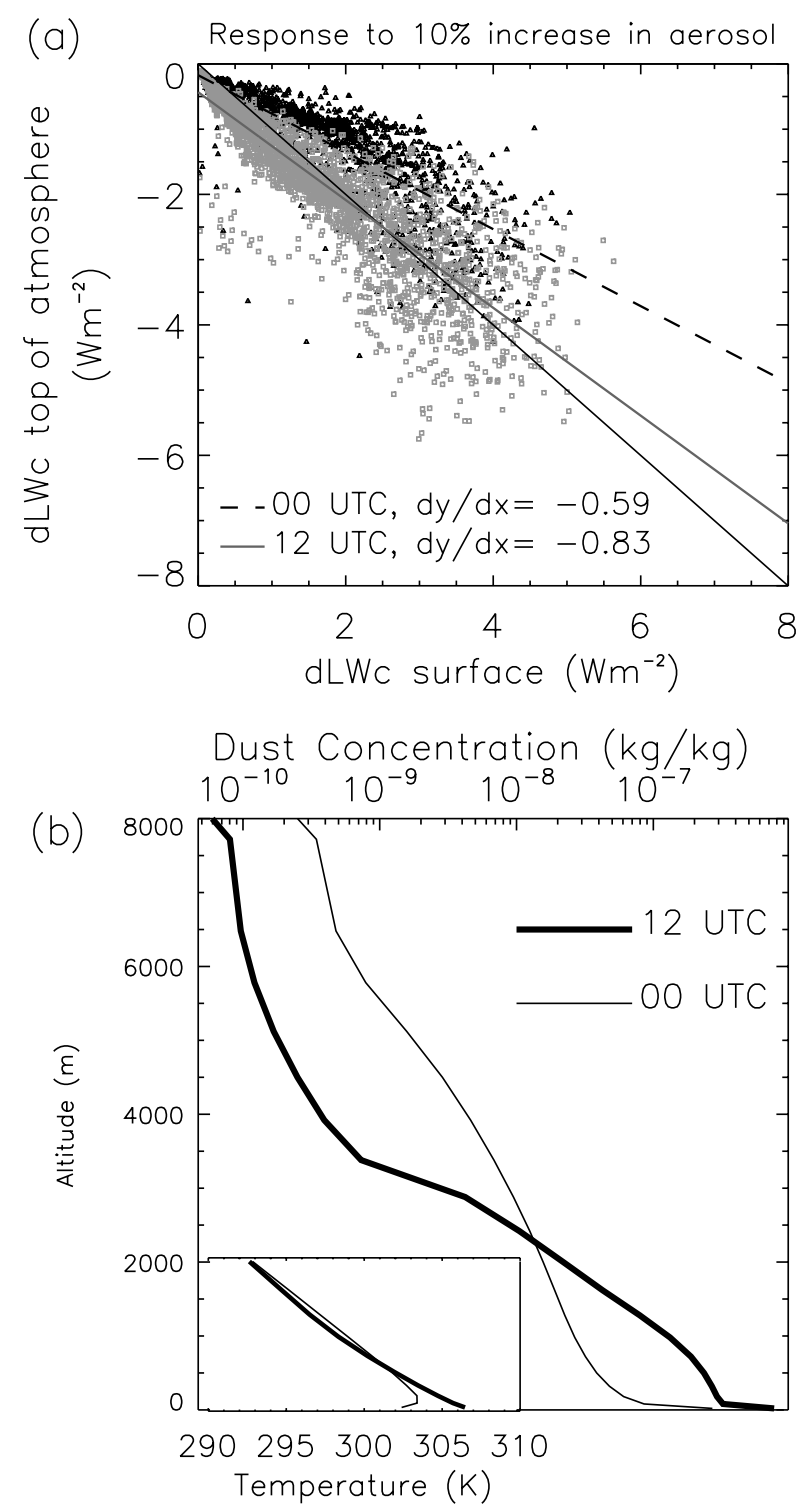

Figure 5. (a) Simulated changes in clear-sky long-wave radiation (LWc) at the top of the atmosphere and the surface in response to a $10 \%$ increase in aerosol concentration at 0000 and 1200 UTC for the period 1-10 July 2000 over the region $10-30^{\circ} \mathrm{N}, 10^{\circ} \mathrm{W}-30^{\circ} \mathrm{E}$. (b) Vertical profiles of dust concentration for the largest particle size bin and air temperature (inset) for the same period and region as (a).

distribution. Dust is emitted when surface wind speeds are high, and lofted higher in the atmosphere when turbulence in the boundary layer is sufficient to mix it upwards (e.g. N’Tchayi Mbourou et al., 1997; Chaboureau et al., 2007; Marsham et al., 2008)

The HiGAM simulations show little diurnal variation in vertical dust concentration for the five smallest size bins. However, the area-mean vertical dust concentration for the largest size bin $(>10 \mu \mathrm{m})$, which exerts the largest influence on LW radiative transfer, displays substantial differences (Figure 5(b)). At 1200 UTC, dust concentration is up to an order of magnitude larger than at 0000 UTC in the lowest $1000 \mathrm{~m}$. The reverse is true above $\sim 3000 \mathrm{~m}$, albeit with substantially lower dust concentration than at lower levels (note the logarithmic scale). The lofting of the largest dust particles above $3000 \mathrm{~m}$ at 0000 UTC is most prominent around $0^{\circ} \mathrm{E}, 25^{\circ} \mathrm{N}$ (not shown). The largest diurnal variation in wind speed simulated by HiGAM occurred around $500 \mathrm{~m}$, with maximum speed around 0000 UTC and minimum at 1500 UTC; the reverse is true near to the surface. In the model, dust emission is related to surface wind speed, so this will be maximum around 1200 UTC. Once lifted from the surface, dust concentration in the vertical depends on turbulent mixing, which will be greatest around 0000 UTC at $500 \mathrm{~m}$. This explains the shapes of the dust profiles in Figure 5(b).

The effect on atmospheric LW radiative cooling is of interest since this links the radiative and dynamical evolution of the atmosphere. At 1200 UTC, dust acts to reduce LWc emitted to space which is approximately balanced by enhanced downwelling LWc at the surface. Thus, reduced cooling to space is approximately compensated by enhanced radiative cooling to the surface. This is of course in addition to considerable atmospheric heating through absorption of SW radiation. Considering a larger dust storm in March 2006, Slingo et al. (2006) found top-of-atmosphere LW dropped by around $30 \mathrm{~W} \mathrm{~m}^{-2}$ at midday and downward surface LW increased by around $50 \mathrm{~W} \mathrm{~m}^{-2}$; this extra atmospheric LW radiative cooling only partially offsets the enhanced atmospheric absorption of SW radiation by the dust aerosol, leading to an overall additional heating at midday of around $100 \mathrm{~W} \mathrm{~m}^{-2}$. However, at 0000 UTC, radiative cooling to the surface dominates over the greenhouse trapping effect on top-of-atmosphere LWc in the model simulations; thus the impact of mineral dust aerosol is to enhance atmospheric SW heating by day (stabilizing temperature profile) and to enhance atmospheric LW radiative cooling at night (destabilizing the temperature profile).

\section{Comparison of GERB satellite data with an NWP model, 2003-2008}

We now place the GERBILS mission in the context of the recent period, 2003-2008, using data from the GERB instrument (Harries et al., 2005) and simulations from the Met Office global NWP model. In contrast to the climate model simulations, considering an NWP framework enables a more direct and consistent comparison approach since data assimilation enhances the realism of the meteorology simulated by the model. Details of the methodology are discussed in Allan et al. (2005) and evaluation of cloud radiative effects in the NWP model is presented in Allan et al. (2007). We focus on the North Africa region. Figure 6 shows a time series of model minus GERB LW and SW differences at $1200 \mathrm{UTC}$ over the region $15-30^{\circ} \mathrm{N}, 15^{\circ} \mathrm{W}-5^{\circ} \mathrm{E}$.

Throughout the whole time series, updates to model physics and ancillary files will also introduce inhomogeneity (Allan et al., 2007). This is particularly evident in the SW comparisons with improvements in model surface albedo and convective cloud over Africa contributing to reduced model SW bias leading up to the GERBILS period (Milton et al., 2008). The improvement in surface albedo is illustrated in Figure 7 ( 3 rd column) which shows progressive reduction in model SWc bias. Model surface albedo was found to be unrealistically high over the Sahara prior to 2005 and was artificially increased to 0.4 on 18 January 2005. This change is evident in Figure 6 as a reduction in the magnitude of model minus GERB albedo, changing from approximately -0.05 up to -0.02 . Less prominent in the time series, but more evident in the model minus GERB SWc bias maps in Figure 7, is the improvement in the spatial 


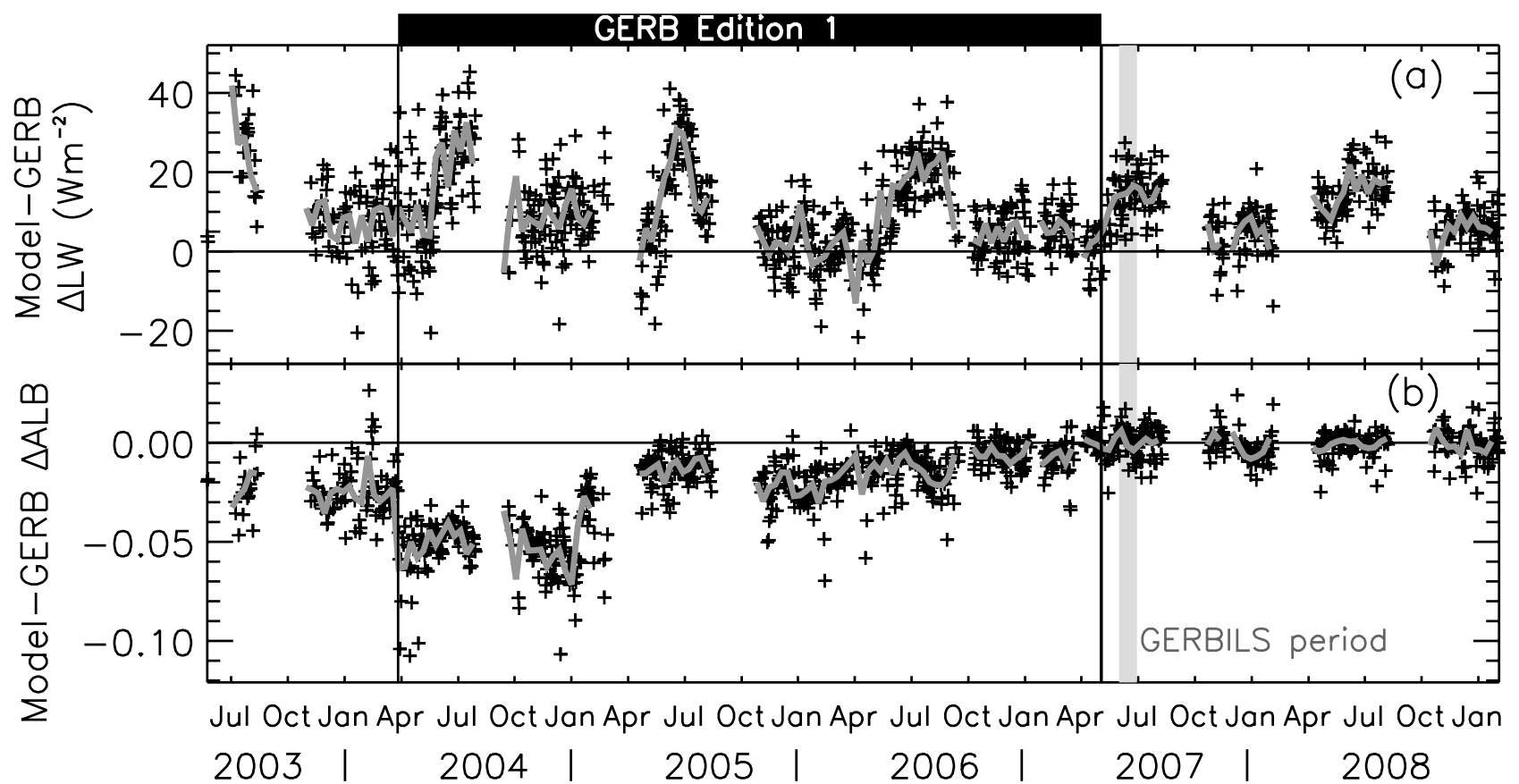

Figure 6. Met Office global forecast model minus GERB: (a) long-wave radiation $(\triangle L W)$ and (b) short-wave albedo ( $\triangle A L B)$ for $1200 \mathrm{UTC}$ data over the region $15-30^{\circ} \mathrm{N}, 15^{\circ} \mathrm{W}-5^{\circ} \mathrm{E}$ from 2003 to 2008 . The 10 -day mean time series are shown as bold grey lines.

structure of simulated SWc after 2006. A more realistic bare soil surface albedo was implemented on 15 May 2007 using MODIS data. A biogenic aerosol climatology was also implemented at this time. Before this, it is plausible that underestimation in model surface albedo may have enhanced surface temperature, explaining a portion of the positive LW bias shown in columns 1-2 (although see section 4.2). Feedbacks complicate simple responses and this was not the case for the climate models considered in sections 3-4. Surface emissivity was reduced from 1.0 to 0.97 on 25 November 2008. Again, based upon the analysis in section 4.2 , it is unlikely that this change will impact the simulation of LW radiation significantly.

The model LW bias over West Africa varies throughout the period, reaching up to $40 \mathrm{~W} \mathrm{~m}^{-2}$ (Figure 6(a)), larger than the anticipated uncertainty in daytime LW of around $10 \mathrm{~W} \mathrm{~m}^{-2}$. There is no evidence of a discontinuity at the end of the Edition 1 GERB period. The bias is systematically larger during the May-July period, one of the motivations for planning the timing of the GERBILS campaign. Figure 6(a) also suggests a decline in the magnitude of the bias over time; there is also evidence of a longer-term decline in dust concentrations since the 1980s relating to increased rainfall (Foltz and McPhaden, 2008). A decline in LW and LWc bias is also evident in spatial maps (Figure 7), although it is not clear whether this relates to improvements in the model, inhomogeneity in the satellite data or reductions in aerosol LW radiative effect. There is little evidence for a decline in AOD at $0.55 \mu \mathrm{m}$ from MISR satellite data.

Over the region $15^{\circ} \mathrm{W}-15^{\circ} \mathrm{E}, 10-30^{\circ} \mathrm{N}$, the model $\mathrm{LWc}$ bias $\left(23 \mathrm{~W} \mathrm{~m}^{-2}\right)$ and MISR AOD (0.54) are at maximum in 2003. The GERB data for this period are preliminary and should be viewed with caution, although analysis of Meteosat-7 data for July 2003 by Haywood et al. (2005) also highlighted a substantial LWc discrepancy of up to $50 \mathrm{~W} \mathrm{~m}^{-2}$. For the remaining years, model minus GERB LWc of $10-15 \mathrm{~W} \mathrm{~m}^{-2}$ and MISR AOD of $0.47-0.52$ were present for this region. The LWc bias may be underestimated for two reasons: (i) the GERB instrument during this period produces lower LW relative to the earlier GERB instrument due to deficiency in the characterization of the quartz filter transmission (Bantges et al., 2010) and (ii) the cloud-screening employed, based upon visible SEVIRI channels, may misclassify high AOD events as cloud. There is also evidence to suggest that satellite estimates of AOD are underestimated compared with in situ aircraft measurements (Christopher et al., 2009).

\section{GERB and NWP model comparisons for June 2007}

We now focus in on the GERBILS period for June 2007. To estimate daily AOD, we combine satellite data from the TOMS OMI instrument with monthly mean MISR data. The TOMS aerosol index is sensitive to both the concentration and the altitude of the mineral dust aerosol; both of these properties are important to the outgoing LW radiation. We calibrate the TOMS data by regressing the monthly mean TOMS AI with MISR AOD at $0.55 \mu \mathrm{m}$ (e.g. Haywood et al., 2005; Christopher et al., 2008) over the region shown in Figure 8 producing the least-squares linear relationship,

$$
A O D_{0.55}=0.245 A I-0.015 \text {. }
$$

Estimated $A O D_{0.55}$ were then generated daily from the TOMS AI. We do not use the MISR daily data directly since the swath width is considered too narrow. Christopher et al. (2008) considered $A I-A O D_{0.55}$ relationships separately for $10^{\circ} \times 10^{\circ}$ regions and found robust relationships for June-August poleward of $10^{\circ} \mathrm{N}$. Since the $0-10^{\circ} \mathrm{N}$ region is dominated by cloud cover (Figure $8(\mathrm{a}, \mathrm{b})$ ), it does not substantially contribute to the linear relationship shown in Figure $8(\mathrm{c})$. Thus we adopt the relationship displayed in Eq. (1) for the North Africa region with the caveat that computed $A O D_{0.55}$ values for $0-10^{\circ} \mathrm{N}$ should be viewed with caution.

Figure 9 shows the mean model minus GERB LW and LWc bias during the GERBILS campaign using 0900, 

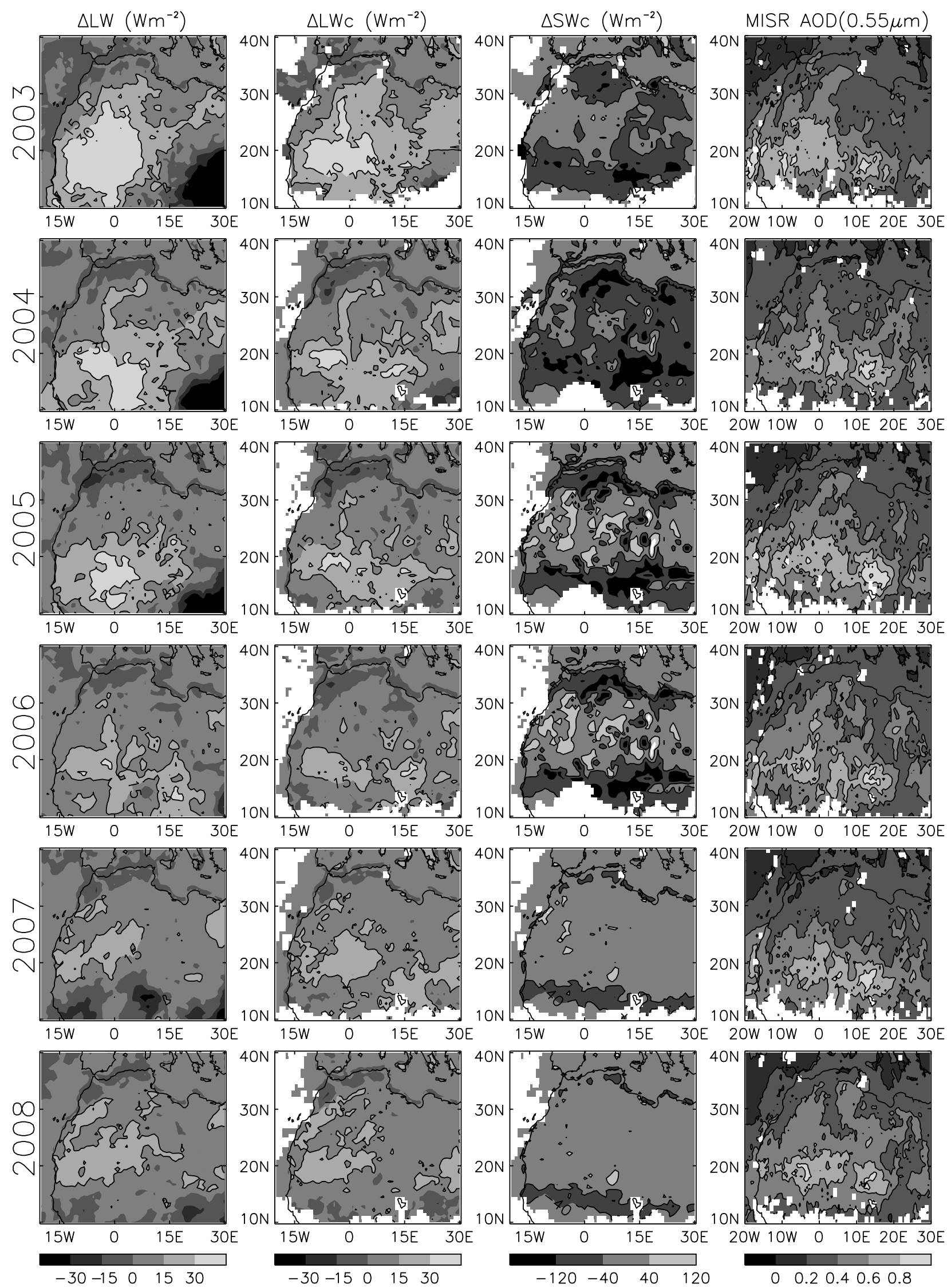

Figure 7. Seasonal mean (May-July) differences from 2003 to 2008 in top-of-atmosphere long-wave (LW), clear-sky LW (LWc) and clear-sky short-wave (SWc) for coincident Met Office global NWP model minus GERB 1200 UTC data and for MISR monthly mean $0.55 \mu \mathrm{m}$ aerosol optical depth. 

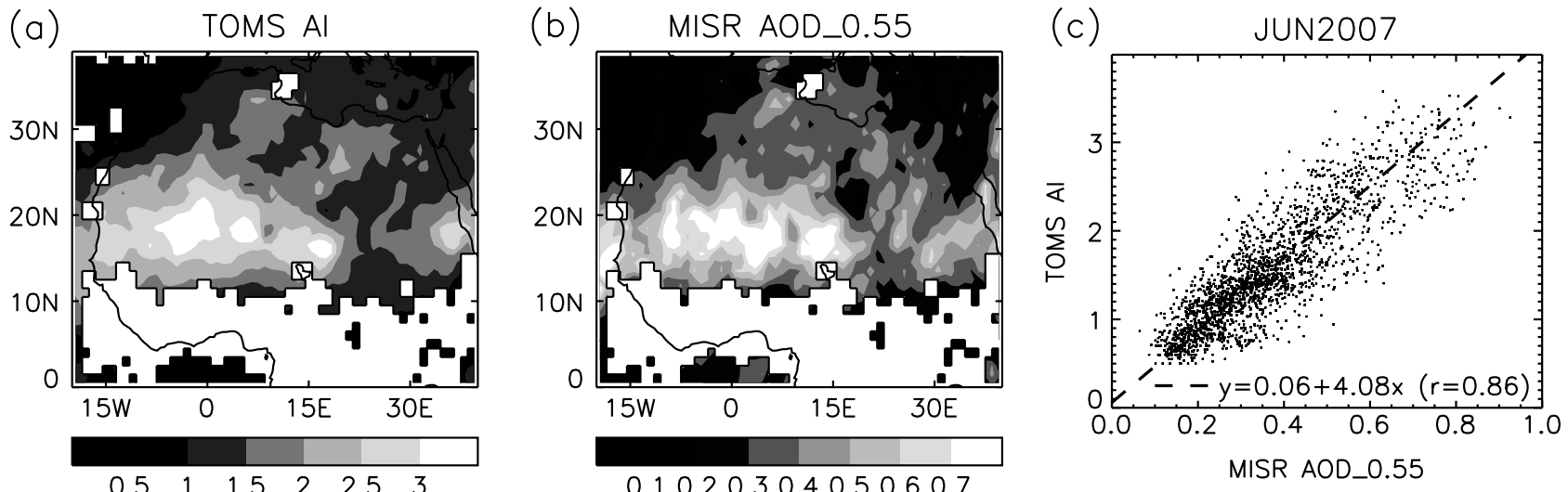

Figure 8. (a) TOMS Aerosol index, (b) MISR aerosol optical depth $(0.55 \mu \mathrm{m})$ and (c) correlation between the two for June 2007.
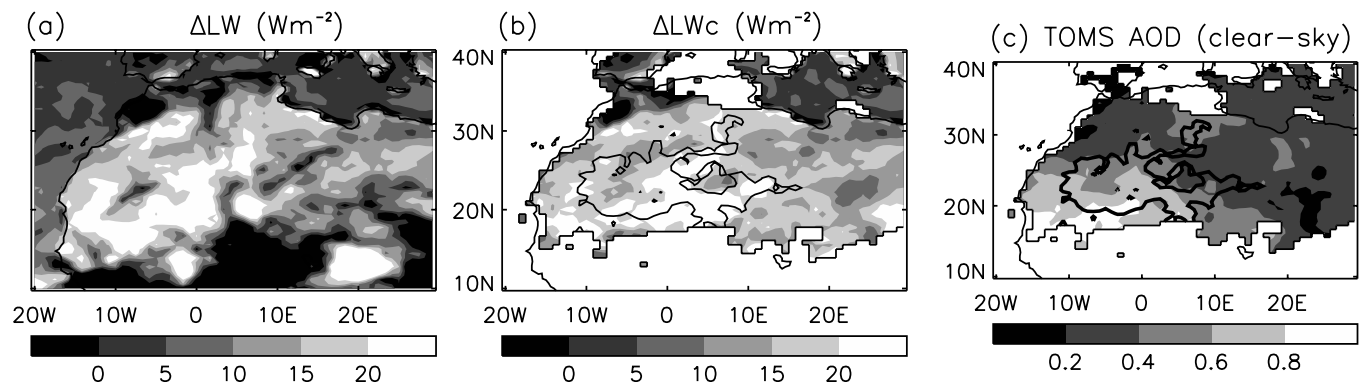

Figure 9. Model minus GERB (a) long-wave (LW) and (b) clear-sky LW differences using 0900, 1200 and 1500 UTC comparisons and (c) cloud-screened TOMS aerosol optical depth during the GERBILS period (18-27 June 2007). In (b) and (c), a contour encloses cloud-screened SEVIRI 10.8-12 $\mu \mathrm{m}$ brightness temperature difference $<+1 \mathrm{~K}$.

1200 and 1500 UTC data. Also shown is the average TOMS estimated cloud-screened AOD (Figure 9(c)). Pixels containing above $1 \%$ cloud fraction in either the model or observed cloud cover maps were screened out to generate clear-sky AOD estimates and LWc comparisons. At least three valid comparisons out of the 30 possible over the period 18-27 June were required to generate a valid mean. Overlaid in Figure $9(b, c)$ is a countour enclosing where SEVIRI cloud-screened average $10.8-12 \mu \mathrm{m}$ brightness temperature difference $\left(B T_{10.8-12}\right)$ is less than $+1 \mathrm{~K}$, symptomatic of detectable mineral dust aerosol loading.

Consistent with the May-July period for 2007 and other years, there is a model overestimation in LW of above $20 \mathrm{~W} \mathrm{~m}^{-2}$ over large portions of the North Africa region. While some of the model-GERB differences relate to cloud, when considering clear-sky comparisons the model bias is clearly evident, in particular over the Sahara. The region of largest bias shows some similarity with the highest AOD from TOMS, although agreement is not high. It is also interesting that the region in which SEVIRI $B T_{10.8-12}<+1 \mathrm{~K}$ does not coincide strongly with the TOMS AOD estimates. One difficulty is that the highest TOMS AOD values are found in the west Sahara equatorward of $20^{\circ} \mathrm{N}$, close to the cloudy regions. This is not surprising since many of the dust events were associated with disturbances generated by convective activity (e.g. Marsham et al., 2008) but they may reduce the number of comparisons contributing to the GERBILS period average.

Figure 10 shows a time series of daily model minus GERB LWc, TOMS-estimated AOD and SEVIRI $B T_{10.8-12}$ during June 2007 for $10^{\circ} \mathrm{W}-10^{\circ} \mathrm{E}, 20-25^{\circ} \mathrm{N}$. For this region, the LWc bias and AOD generally rise over the period 5-19 June, reaching $\mathrm{LWc}$ differences above $20 \mathrm{~W} \mathrm{~m}^{-2}$ and AOD of 0.7 .
They decline over 19-23 June, remaining stable thereafter with $\mathrm{LWc}$ differences below $20 \mathrm{~W} \mathrm{~m}^{-2}$ and AOD of around 0.5. Correlation between TOMS AOD and $\triangle \mathrm{LWc}(r=0.61)$ and between SEVIRI $B T_{10.8-12}$ and $\triangle \mathrm{LWc}(r=0.48)$ are significant at the $95 \%$ level assuming 17 degrees of freedom, accounting for autocorrelation of the $\Delta \mathrm{LWc}$ timeseries using the method of Yang and Tung (1998). Relationships for other regions are not found to be significant.

Maps of AOD and LW differences (Figure 11) show regions of high AOD during 18-22 June coinciding with model minus GERB LW differences of around $30 \mathrm{~W} \mathrm{~m}^{-2}$. The regions of largest difference track westward with lower AOD and LW differences thereafter. Negative SEVIRI brightness temperature differences (contours) match well with the highest AOD estimated by TOMS, in contrast to the comparisons of time-means in Figure 9. Contours overlaid upon the LW differences enclose regions of cloud cover greater than $20 \%$ in either the model or the satellite estimates. Here LW differences are likely to be affected by discrepancies in cloud fraction and/or type and are associated with both positive and negative LW differences. Detected cloud cover in the satellite data at the heart of the dust event on 18-19 June is likely to be misclassified dust.

Christopher et al. (2009) found AOD of around 1 on 21 June around $14^{\circ} \mathrm{N}, 14^{\circ} \mathrm{W}$ in OMI and MISR data, lower than in situ aircraft measurements. This is consistent with the identified dust region in Figure 11, although the influence on LW is impacted by the presence of cloud. Johnson et al. (2011) identified this dust layer over southern Mali and found it to be mainly located between 2 and $4.5 \mathrm{~km}$ on 21 June. Osborne et al. (2011) found a LW radiative effect of dust aerosol of around $14 \mathrm{~W} \mathrm{~m}^{-2}$ on 25 June at 


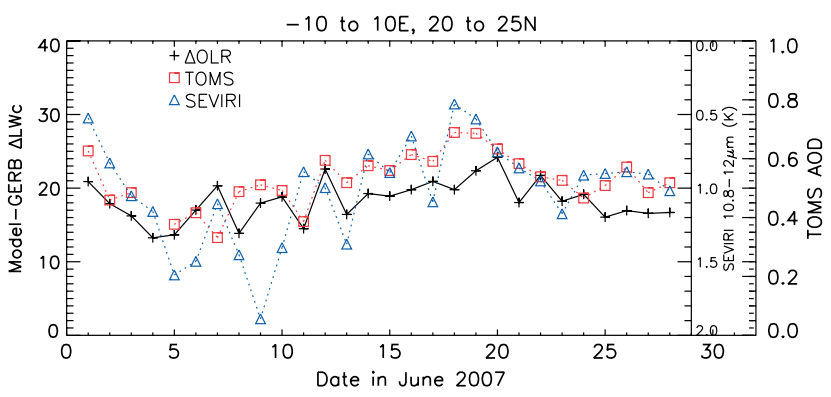

Figure 10. Changes in cloud-screened daily model minus GERB outgoing long-wave radiation (LWc) and SEVIRI $10.8-12 \mu \mathrm{m}$ brightness temperature difference (both averages of 0900, 1200 and 1500 UTC comparisons) and TOMS estimated aerosol optical depth (AOD) for June 2007 over the region $10^{\circ} \mathrm{W}-10^{\circ} \mathrm{E}, 20-25^{\circ} \mathrm{N}$.

around $18^{\circ} \mathrm{N}, 6.5^{\circ} \mathrm{W}$; again the LW comparisons for this region are affected by cloud cover although model-GERB differences of order $10 \mathrm{~W} \mathrm{~m}^{-2}$ are apparent. Over the larger region, away from the influence of cloud, model minus GERB LW differences of up to $30 \mathrm{~W} \mathrm{~m}^{-2}$ are evident (Figure 11), consistent with other years (Figure 7) and with systematic LW bias found in climate models (Figures 1-3).

\section{Conclusions}

Satellite data are used to quantify and examine an overestimation in the outgoing LW radiation over North Africa previously identified in the Met Office global forecast model (Haywood et al., 2005). Simulations from an ensemble-mean of multiple climate models over the period 1985-2000 for May-July overestimate outgoing LWc radiation by more than $20 \mathrm{~W} \mathrm{~m}^{-2}$ relative to ERBS and CERES satellite observations over parts of the west Sahara and by around $10 \mathrm{~W} \mathrm{~m}^{-2}$ for the North Africa region $\left(20^{\circ} \mathrm{W}-30^{\circ} \mathrm{E}, 10-40^{\circ} \mathrm{N}\right)$. Models that did not represent mineral dust aerosol were found to contain the largest LW discrepancy. However considerable bias remained for many of the models that did represent the aerosol radiative effects, suggesting that the dust amount, distribution and radiative properties may be poorly parametrized for the May-July period.

A similar LW bias found in simulations from a highresolution atmosphere-only climate model (HiGAM) is reduced when mineral dust is explicitly included (Woodage et al., 2010) within the simulations. Only by reducing surface temperature and emissivity by unrealistic amounts in this model is it possible to reproduce the magnitude of the bias in the west Sahara. Elsewhere, it is likely that unrealistic surface emissivity and temperature contribute to differences in outgoing LW radiation. In these model simulations, the direct dust LW radiative effect at the surface and top of atmosphere are of comparable magnitude at $1200 \mathrm{UTC}$, reaching $5 \mathrm{~W} \mathrm{~m}^{-2}$ for a $10 \%$ increase in dust concentrations. Hansell et al. (2010) also found, using surface observations and modelling, a compensating surface and top-of-atmosphere LW radiative effect, increasing at the surface by $16 \mathrm{~W} \mathrm{~m}^{-2}$ per unit AOD and by $13 \mathrm{~W} \mathrm{~m}^{-2}$ per unit AOD at the top of atmosphere. The atmospheric LW radiative effect during the day is small but non-negligible compared to the heating effect through SW absorption (Slingo et al., 2006). At 0000 UTC the top-of-atmosphere LWc effect of changes in dust concentration is around half
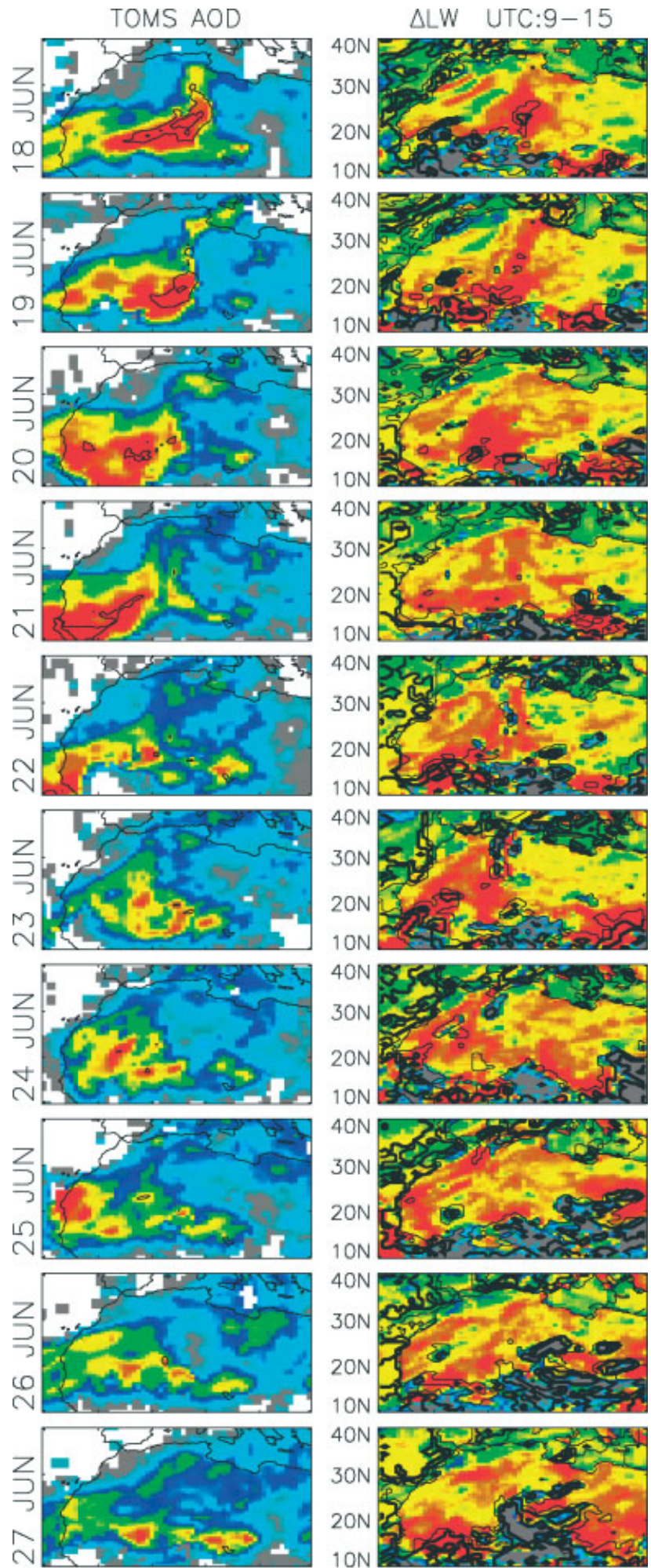

2OW 10W O 10E $20 E$

$\begin{array}{lllll}0.2 & 0.4 & 0.6 & 0.8 & 1\end{array}$
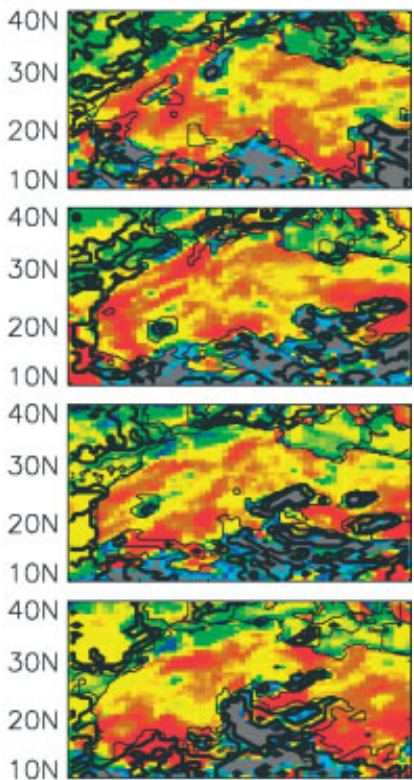

2OW 10W O 10E $20 \mathrm{E}$

$-30-20-100 \quad 102030$

Figure 11. TOMS Aerosol Optical Depth (left column) and model minus GERB outgoing long-wave radiation $\left(\triangle \mathrm{LW}, \mathrm{W} \mathrm{m}^{-2}\right.$; right column) for 0900, 1200 and 1500 UTC averages over the period 18-27 June 2007. The left panels also show SEVIRI $10.8-12 \mu \mathrm{m}$ brightness temperature differences (contours at $-4,-2$ and $0 \mathrm{~K}$ ) and the right panels show contours where model or SEVIRI cloud fraction is equal to $20 \%, 50 \%$ and $80 \%$.

of the surface LWc effect, for the HiGAM model, leading to a direct enhancement of atmospheric LW radiative cooling by dust aerosol at night. 
Comparing simulations from the Met Office global forecast model with satellite observations from GERB instruments, overestimates in simulated LW of $20-40 \mathrm{~W} \mathrm{~m}^{-2}$ are evident during the summer over North Africa. The bias declines over the period 2003-2008; this is likely to relate to improvements in the model and inhomogeneity in the satellite time series. A change in GERB instrument early in 2007 introduced a change in LW fluxes although preliminary analysis suggests that this acts to reduce the model-GERB LW differences (Bantges et al., 2010); planned improvements in the calibration of the new GERB instrument will reduce this effect.

The bias in LWc coincides with high aerosol dust loading estimated from the OMI, including during the GERBILS field campaign (18-28 June 2007) where model overestimates in daytime mean LWc greater than $20 \mathrm{~W} \mathrm{~m}^{-2}$ and OMI-estimated AOD greater than 0.8 are concurrent around $20^{\circ} \mathrm{N}, 0-20^{\circ} \mathrm{W}$. High daily AOD and LW model-GERB bias of up to $30 \mathrm{~W} \mathrm{~m}^{-2}$ coincide during the period 18-21 June 2007, although differences in cloud cover also impact the model-GERB differences; further work is required to improve the observed estimates of mineral dust radiative effects by better accounting for the influence of cloud cover sampling effects and the development of angular dependence models for mineral dust aerosol (Brindley and Russell, 2009). It is anticipated that much of the remaining LW bias in the NWP model will be removed by the use of a monthly, three-dimensional, aerosol climatology generated from the HadGEM series of climate models.

In summary, there is evidence from a variety of satellite sensors that global models underestimate or neglect the LW radiative effect of mineral dust aerosol over the west Sahara during May-July as previously identified by Haywood et al. (2005). Including mineral dust aerosol explicitly in model simulations reduces this bias considerably. Woodage et al. (2010) found that inclusion of mineral dust in HiGAM model simulations induced dynamical feedbacks on the atmospheric circulation which affected the dust production itself. This implies that models which include accurate dust parametrizations are likely to improve their forecast accuracy and their ability to correctly simulate weather patterns and climate over North Africa and the North Atlantic (Tompkins et al., 2005; Kim et al., 2010; Li and Min, 2010); improvement in the representation of mineral dust processes in models requires the careful analysis and combination of detailed in situ measurements with satellite data (e.g. Christopher et al., 2009; Osborne et al., 2011).

\section{Acknowledgements}

This research was supported by the UK NERC grant $\mathrm{NE} / \mathrm{C} 51785 \mathrm{X} / 1$ and the National Centre for Earth Observation. The GERB data were taken from the GERB Ground Segment Processing System and RMIB archives, the MISR and CERES data from the NASA Langley Atmospheric Science Data Center, the TOMS OMI data from http://jwocky.gsfc.nasa.gov and the CRUTEM3 data from the Climatic Research Unit, Norwich. We acknowledge the modelling groups, the Programme for Climate Model Diagnosis and Intercomparison and the World Climate Research Programme's Working Group on Coupled Modelling for their roles in making available the WCRP CMIP3 multi-model dataset. Support of this dataset is provided by the Office of Science, US Department of
Energy. HiGAM experiments were carried out using the High End Computing Terascale Resources at Edinburgh University, funded by the UK Research Councils. We thank two anonymous reviewers for their input.

\section{References}

Allan RP, Ringer MA. 2003. Inconsistencies between satellite estimates of longwave cloud forcing and dynamical fields from reanalyses. Geophys. Res. Lett. 30: 1491, DOI: 10.1029/2003GL017 019.

Allan RP, Slingo A, Milton SF, Culverwell I. 2005. Exploitation of geostationary earth radition budget data using simulations from a numerical weather prediction model: Methodology and data validation. J. Geophys. Res. 110(D14111): DOI: 10.1029/2004JD005 698.

Allan RP, Slingo A, Milton SF, Brooks ME. 2007. Evaluation of the Met Office global forecast model using Geostationary Earth Radiation Budget (GERB) data. Q. J. R. Meteorol. Soc. 133: 1993-2010.

Bantges R, Russell JE, Clerbaux N 2010. Report on the inter-comparison of data from the GERB-1 and GERB-2 instruments using data from periods of simultaneous operation, MSG-ICL-GE-RP-0036, pp 128, available from the Rutherford Appleton Laboratory and EUMETSAT.

Bony S, Colman R, Kattsov VM, Allan RP, Bretherton CS, Dufresne JL, Hall A, Hallegatte S, Holland MM, Ingram W, Randall DA, Soden BJ, Tselioudis G, Webb MJ. 2006. How well do we understand and evaluate climate change feedback processes? J. Climate 19:3445-3482.

Brindley HE, Russell JE. 2009. An assessment of Saharan dust loading and the corresponding cloud-free longwave direct radiative effect from geostationary satellite observations. J. Geophys. Res. 114: D23201, DOI: $10.1029 / 2008$ JD011635.

Brohan P, Kennedy JJ, Harris I, Tett SFB, Jones PD. 2006. Uncertainty estimates in regional and global observed temperature changes: A new data set from 1850. J. Geophys. Res. 111: D12106+, DOI: 10.1029/2005JD006548.

Chaboureau JP, Tulet P, Mari C. 2007. Diurnal cycle of dust and cirrus over West Africa as seen from Meteosat Second Generation satellite and a regional forecast model. Geophys. Res. Lett. 34: L02822, DOI: 10.1029/2006GL027771.

Christopher SA, Gupta P, Haywood J, Greed G. 2008. Aerosol optical thicknesses over North Africa: 1. Development of a product for model validation using Ozone Monitoring Instrument, Multiangle Imaging Spectroradiometer, and Aerosol Robotic Network. J. Geophys. Res. 113: D00C04, DOI: 10.1029/2007JD009446.

Christopher SA, Johnson B, Jones TA, Haywood J. 2009. Vertical and spatial distribution of dust from aircraft and satellite measurements during the GERBILS field campaign. Geophys. Res. Lett. 36: L06806, DOI: $10.1029 / 2008$ GL037033.

Clerbaux N, Dewitte S, Bertrand C, Caprion D, De Paepe B, Gonzalez L, Ipe A, Russell JE, Brindley HE. 2008a. Unfiltering of the Geostationary Earth Radiation Budget (GERB) data. Part I: Shortwave radiation. J. Atmos. Oceanic Technol. 25: 1087-1105.

Clerbaux N, Dewitte S, Bertrand C, Caprion D, De Paepe B, Gonzalez L, Ipe A, Russell JE. 2008b. Unfiltering of the Geostationary Earth Radiation Budget (GERB) data. Part II: Longwave radiation. J. Atmos. Oceanic Technol. 25: 1106-1117.

Clerbaux N, Russell JE, Dewitte S, Bertrand C, Caprion D, De Paepe B, Gonzalez-Sotelino L, Ipe A, Bantges R, Brindley HE. 2009. Comparison of GERB instantaneous radiance and flux products with CERES Edition-2 data. Remote Sens. Environ. 113: 102-114.

Diner DJ, Abdou WA, Bruegge CJ, Conel JE, Crean KA, Gaitley BJ, Helmlinger MC, Kahn RA, Martonchik JV, Pilorz SH, Holben BN. 2001. MISR aerosol optical depth retrievals over southern Africa during the SAFARI-2000 dry season campaign. J. Geophys. Res. 28: 3127-3130

Foltz GR, McPhaden MJ. 2008. Trends in Sahara dust and tropical Atlantic climate during 1980-2006. Geophys. Res. Lett. 35: L20706, DOI: $10.1029 / 2008$ GL035042.

Forster P, Ramaswamy V, Artaxo P, Berntsen T, Betts R, Fahey D, Haywood J, Lean J, Lowe D, Myhre G, Nganga J, Prinn R, Raga G, Schulz M, Dorland RV. 2007. Changes in atmospheric constituents and in radiative forcing. Chapter 2 in Climate Change 2007: The Physical Science Basis. Contribution of Working Group I to the Fourth Assessment Report of the Intergovernmental Panel on Climate Change. Cambridge University Press: Cambridge, UK and New York. 129-234.

Hansell RA, Ji Q, Tsay SC, Hsu NC, Jeong MJ, Wang SH, Reid JS, Liou KN, Ou SC. 2010. An assessment of the surface longwave direct 
radiative effect of airborne Saharan dust during the NAMMA field campaign. J. Atmos. Sci. 67: 1048-1065.

Harries JE, Russell JE, Hanafin JA, Brindley HE, Futyan J, Rufus J, Kellock S, Matthews G, Wrigley R, Last A, Mueller J, Mossavati R, Ashmall J, Sawyer E, Parker D, Caldwell M, Allan PM, Smith A, Bates MJ, Coan B, Stewart BC, Lepine DR, Cornwall LA, Corney DR, Ricketts MJ, Drummond D, Smart D, Cutler R, Dewitte S, Clerbaux N, Gonzalez L, Ipe A, Bertrand C, Joukoff A, Crommelynck D, Nelms N, Llewellyn-Jones DT, Butcher G, Smith GL, Szewczyk ZP, Mlynczak PE, Slingo A, Allan RP, Ringer MA. 2005. The Geostationary Earth Radiation Budget (GERB) experiment. Bull. Amer. Meteorol. Soc. 86: 945-960.

Haywood JM, Allan RP, Culverwell I, Slingo A, Milton S, Edwards JM, Clerbaux N. 2005. Can desert dust explain the anomalous greenhouse effect observed over the Sahara during July 2003? J. Geophys. Res. 110: DOI: 10.1029/2004JD005 232.

Haywood JM, Johnson BT, Osborne SR, Baran AJ, Brooks M, Milton SF, Mulcahy J, Walters D, Allan RP, Woodage MJ, Klaver A, Formenti P, Brindley HE, Christopher S, Gupta P. 2011. Motivation, rationale and key results from the GERBILS Saharan dust measurement campaign. Q. J. R. Meteorol. Soc. 137: 1106-1116, DOI: 10.1002/qj.797.

Houldcroft C, Grey WMF, Barnsley M, Taylor CM, Los SO, North PRJ. 2009. New vegetation albedo parameters and global fields of soil background albedo derived from MODIS for use in a climate model. J. Hydrometeorol. 10: 183-198.

Ipe A, Clerbaux N, Bertrand C, Dewitte S, Gonzalez L. 2004. Validation and homogenisation of cloud optical depth and cloud fraction retrievals for GERB/SEVIRI scene identification using Meteosat-7 data. Atmos. Res. 72: 17-37.

Johnson BT, Brooks ME, Walters D, Woodward S, Christopher S, Schepanski K. 2011. Assessment of the Met Office dust forecast model using observations from the GERBILS campaign. Q. J. R. Meteorol. Soc. 137: 1131-1148, DOI: 10.1002/qj.736.

Jones PD, New M, Parker DE, Martin S, Rigor IG. 1999. Surface air temperature and its changes over the past 150 years. Rev. Geophys. 37: 173-199.

Kim K, Lau WKM, Sud YC, Walker GK. 2010. Influence of aerosolradiative forcings on the diurnal and seasonal cycles of rainfall over West Africa and Eastern Atlantic Ocean using GCM simulations. Clim. Dyn. 35: 115-126.

Li R, Min Q. 2010. Impacts of mineral dust on the vertical structure of precipitation. J. Geophys. Res. 115: D09203, DOI: 10.1029/2009JD011925.

Loeb NG, Wielicki BA, Doelling DR, Smith GL, Keyes DF, Kato S, Manalo-Smith N, Wong T. 2009. Toward optimal closure of the Earth's top of atmosphere radiation budget. J. Climate 22: 748-766.

Marsham JH, Parker DJ, Grams CM, Taylor CM, Haywood JM. 2008. Uplift of Saharan dust south of the intertropical discontinuity. J. Geophys. Res. 113: D21102, DOI: 10.1029/2008JD009844.

Matthews G. 2009. In-flight spectral characterization and calibration stability estimates for the Clouds and the Earth's Radiant Energy System (CERES). J. Atmos. Oceanic Technol. 26: 1685-1716.

Milton SF, Greed G, Brooks ME, Haywood JM, Johnson B, Allan RP, Slingo A, Grey WMF. 2008. Modeled and observed atmospheric radiation balance during the West African dry season: Role of mineral dust, biomass burning aerosol, and surface albedo. J. Geophys. Res. 113: D00C02, DOI: 10.1029/2007JD009741.
N’Tchayi Mbourou G, Bertrand JJ, Nicholson SE. 1997. The diurnal and seasonal cycles of wind-borne dust over Africa north of the Equator. J. Appl. Meteorol. 36: 868-882.

Osborne SR, Baran AJ, Johnson BT, Haywood JM, Hesse E, Newman S. 2011. Short-wave and long-wave radiative properties of Saharan dust aerosol. Q. J. R. Meteorol. Soc. 137: 1149-1167, DOI: 10.1002/qj.771.

Randall DA, Wood R, Bony S, Colman R, Fichefet T, Fyfe J, Kattsov V, Pitman A, Shukla J, Srinivasan J, Stouffer R, Sumi A, Taylor K. 2007. Climate models and their evaluation. Chapter 8 in Climate Change 2007: The Physical Science Basis. Contribution of Working Group I to the Fourth Assessment Report of the Intergovernmental Panel on Climate Change. Cambridge University Press: Cambridge, UK and New York. 589-662.

Shaffrey LC, Norton WA, Cole JW, Slingo JM, Steenman-Clark L, Stevens I, Stevens DP, Roberts MJ, Clayton A, Vidale PL, Demory ME Donners J, Harle JD, New AL, Jrrar A, Connolley WM, King JC, Woodage MJ, Slingo A, Clark DB, Wilson SS, Davies TM, Iwi AM, Johns TC, Martin GM. 2009. UK HiGEM: The new UK Highresolution Global Environment Model - Model description and basic evaluation. J. Climate 22: 1861-1896.

Slingo A, Ackerman TP, Allan RP, Kassianov EI, McFarlane SA, Robinson GJ, Barnard JC, Miller MA, Harries JE, Russell JE, Dewitte S. 2006. Observations of the impact of a major Saharan dust storm on the atmospheric radiation balance. Geophys. Res. Lett. 33: L24817, DOI: 10.1029/2006GL027869.

Slingo A, Bharmal NA, Robinson GJ, Settle JJ, Allan RP, White HE, Lamb PJ, Issa Lèlè MI, Turner DD, McFarlane S, Kassianov E, Barnard J, Flynn C, Miller M. 2008. Overview of observations from the RADAGAST experiment in Niamey, Niger. Part 1: Meteorology and thermodynamic variables. J. Geophys Res., 113: D00E01, DOI:10.1029/2008JD009909.

Tompkins AM, Cardinali C, Morcrette J, Rodwell M. 2005. Influence of aerosol climatology on forecasts of the African Easterly Jet. Geophys. Res. Lett. 32: L10801, DOI: 10.1029/2004GL022189.

Torres O, Bhartia PK, Herman JR, Sinyuk A, Ginoux P, Holben B. 2002. A long-term record of aerosol optical depth from TOMS observations and comparison to AERONET measurements. J. Atmos. Sci. 59: 398-413.

Trenberth K, Stepaniak D. 2004. The flow of energy through the earth's climate system. Q. J. R. Meteorol. Soc. 130: 2677-2701.

Wielicki BA, Wong T, Allan RP, Slingo A, Kiehl JT, Soden BJ, Gordon CT, Miller AJ, Yang S, Randall DA, Robertson F, Susskind J, Jacobowitz H. 2002. Evidence for large decadal variability in the tropical mean radiative energy budget. Science 295: 841-844.

Woodage MJ, Slingo A, Woodward S, Comer RE. 2010. UKHiGEM: Simulations of desert dust and biomass burning aerosols with a high-resolution atmospheric GCM. J. Climate 23: 1636-1659.

Woodward S. 2001. Modeling the atmospheric life cycle and radiative impact of mineral dust in the Hadley Centre climate model. J. Geophys. Res. 106: 18155-18166.

Yang H, Tung KK. 1998. Water vapor, surface temperature, and the greenhouse effect - A statistical analysis of tropical-mean data J. Climate 11: 2686-2697.

Zhang J, Christopher S. 2003. Longwave radiative forcing of Saharan dust aerosols estimated from MODIS, MISR, and CERES observations on Terra. Geophys. Res. Lett. 30: 2188, DOI: 10.1029/2003GL018479. 